\title{
Associations between respiratory symptoms, bronchial response to methacholine, and atopy in two age groups of schoolchildren
}

\author{
R D CLIFFORD,${ }^{*} \dagger$ J B HOWELL,${ }^{*}$ M RADFORD,$\dagger$ AND S T HOLGATE $*$ \\ Departments of ${ }^{*}$ Medicine and + Child Health, University of Southampton
}

SUMMARY Data on respiratory symptoms were obtained on 2503 schoolchildren aged 7 and 11 in Southampton by means of a self administered parental questionnaire. Children were classified into seven symptom groups from which 330 were tested for bronchial responsiveness to $\leqslant 6.4$ $\mu \mathrm{mol}$ methacholine and skin tested for the presence of atopy. The symptoms of wheeze, cough, and shortness of breath were all significantly associated both with each other and bronchial responsiveness to methacholine but only wheeze was associated with atopy. The association of wheeze with both bronchial responsiveness to methacholine and atopy remained highly significant when controlling for the symptoms of cough and shortness of breath. Neither cough nor shortness of breath, however, were significantly related to bronchial responsiveness to methacholine when controlling for the symptom of wheeze. This study therefore calls into question the epidemiological relevance of these two symptoms as diagnostic features of asthma, particularly in the absence of wheeze, although they may be useful indicators of morbidity.

Wheeze was not related to bronchial responsiveness to methacholine in the absence of atopy or to atopy in the absence of bronchial responsiveness to methacholine but was strongly related to the combination of the two phenomena. The presence of these three characteristics could therefore indicate a discrete disease entity. The decrease in the prevalence of cough between 7 and 11 years appeared to be mirrored by a similar decrease in the prevalence of wheeze when the symptom was not associated with the combination of bronchial responsiveness to methacholine and atopy. On the basis of these findings and those of others we suggest that the latter group may represent children with a separate disease entity(ies) or with residual symptoms secondary to acute viral or other infections of the lower respiratory tract.

The epidemiology of asthma is of importance in the study of both temporal and geographical changes in the prevelance of the disorder and its possible causes. ${ }^{1}$ Cross sectional studies of asthma prevalence using subject recall of previous medical diagnoses have failed to achieve their aims largely because of the frequent underdiagnosis of the condition. ${ }^{2}$ Although studies of childhood asthma which have concentrated upon the symptom of recurrent wheeze have provided much useful information, the precise association of the prevalence of this symptom to the prevalence of asthma is unknown. Some children with asthma present with symptoms other than wheeze, although it is not known how many of these would answer negatively to a question on the symptom. On the other hand intermittent symptoms similar to asthma are known to occur for years after acute episodes of bronchiolitis $^{34}$ and pertussis, ${ }^{5}$ but disappear with increasing age $^{34}$ and are probably unrelated to the presence of atopy $^{67}$ or a family history of asthma. ${ }^{7}$

The provocation of acute airways obstruction using non-specific agents such as exercise, inhalation of cold air, histamine, or methacholine as indirect or direct indices of non-specific bronchial responsiveness has a long history in the study of asthma but has only recently been used in large scale epidemiological studies in adults ${ }^{8}$ and children. ${ }^{9}$ However, the association of non-specific bronchial hyperresponsiveness to asthma is no clearer than that of 
wheeze. For instance, a large overlap is known to occur in levels of measurable bronchial responsiveness between asymptomatic and clearly symptomatic individuals and is particularly obvious in children. ${ }^{10}$ There have been a number of studies linking the presence of atopy to asthma but the role of this immunological abnormality as a defining characteristic of asthma is also unclear.

We have previously described the results of a questionnaire survey of respiratory symptoms in 2503 Southampton schoolchildre ${ }^{11}$ and in a second paper the results of methacholine bronchial provocation with allergin skin testing of 332 of the same children selected on the basis of symptom group. ${ }^{12}$ We now present the associations found between symptoms and the results of bronchial provocation and allergen skin testing in 7 and 11 year old children from the same population.

\section{Subjects and methods}

\section{QUESTIONNAIRE STUDY}

All children within the age groups $6 \cdot 8-7 \cdot 8$ years $(7$ year olds) and 10.8-11.8 years (11 year olds) in 55 schools in the urban environment of Southampton were included in the study. The questionnaire, which has been described elsewhere, ${ }^{11}$ contained questions designed to identify current and past symptoms of wheeze, shortness of breath, and cough in addition to provoking factors.

BRONCHIAL PROVOCATION AND ALLERGIN SKIN PRICK TESTING

Children were placed into one of seven mutually exclusive symptom groups according to the answers provided on the respiratory questionnaire (table 1). ${ }^{12}$ These groups mainly related to the symptoms of wheeze, cough, and shortness of breath but also included a group of children whose parents had answered negatively to those sections of the questionnaire but positively when asked about the effect of a number of environmental irritants. For brevity, this group was classed as having 'bronchial irritability'. With the exception of group 7, each symptom group referred to symptoms within 12 months from delivery of the questionnaire. Four hundred children were selected from these groups for methacholine bronchial provocation and allergen skin prick testing of whom 341 attended, 330 being successfully tested for bronchial responsiveness and 329 for atopy. ${ }^{12}$

The methodologies used for the bronchial provocation and allergen skin prick tests have been described in detail elsewhere. ${ }^{12} 13$ The cumulative provocation dose of methacholine required to cause a $20 \%$ fall in forced expiratory volume in one second
Table 1 Proportion of children within each symptom group, response to methacholine, and allergen skin testing

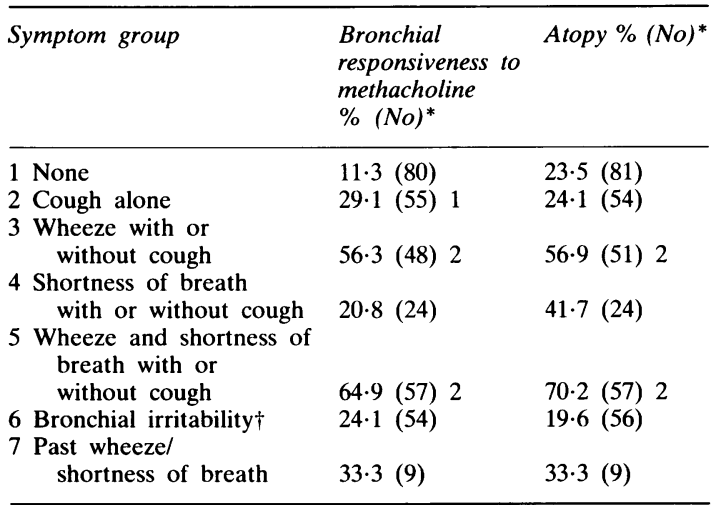

*Percentage of number of children tested (No) in that symptom group who displayed the characteristic.

†See text for explanation of symptom group.

$\chi^{2}$ tests: all symptoms $v$ atopy: $\mathrm{p}<0.001$; all symptoms $v$ bronchial responsiveness to methacholine: $\mathrm{p}<0 \cdot 001$; each symptom group $v$ no symptoms: $1, \mathrm{p}<0 \cdot 02: 2, \mathrm{p}<0.0001$ : other differences not significant.

$\left(F E V_{1}\right)$ from a postsaline baseline $\left(\mathrm{PD}_{20}\right.$ methacholine) was calculated from the log-dose response curve by linear interpolation. As most children did not respond to even high doses of methacholine, they were divided into those with $\mathrm{PD}_{20}$ values of less than or greater than $6.4 \mu \mathrm{mol}$, the top dose of constrictory agonist used in this study. It was thus possible to show that one group was more methacholine responsive than another but not by how much. For convenience we have classified these children with a $\mathrm{PD}_{20}$ methacholine of $\leqslant 6.4 \mu \mathrm{mol}$ as having the characteristic of bronchial responsiveness to methacholine but the arbitrary nature of this classification should not be forgotten. Fifteen children with an $\mathrm{FEV}_{1}<75 \%$ expected for height were not tested but showed reversability with salbutamol. These children were therefore classified within the group with bronchial responsiveness to methacholine for the purpose of analysis.

Three allergen extracts, house dust mite (Dermatophagoides pteronyssinus), mixed grass pollens and cat dander (Bencard) were used for skin prick testing. Children with one or more positive results, when compared with appropriate controls, were classed as atopic. ${ }^{1+15}$

\section{STATISTICAL ANALYSIS}

The Statistical Package for Social Sciences edition X was used for categorisation and analysis of data. ${ }^{16}$ Correlations between variables were calculated 
using $\chi^{2}$ analyses and the Mantel-Haenszel test where appropriate. ${ }^{17}$

\section{Results}

Bronchial responsiveness to methacholine, as defined above, was shown to occur in $111(33.6 \%)$ of the 330 children tested and a positive immediate response to allergen skin testing (atopy) was found in $125(38.0 \%)$ of 329 children tested. The two symptom groups containing children with wheeze (table 1: groups 3 and 5) included the highest proportions with bronchial responsiveness to methacholine and with atopy. Testing by $\chi^{2}$ of the overall association between symptoms and bronchial responsiveness to methacholine showed this to be highly significant $(p<0.001)$. The associations between symptoms and the presence of a positive skin response to each of the three allergens was also highly significant $(p<0 \cdot 001$ in each case). When compared with children without symptoms, the associations between the reported symptom of wheeze and bronchial responsiveness to methacholine and between wheeze and atopy were highly significant. Nevertheless of 105 children with wheeze, 42 did not display bronchial responsiveness to methacholine and 39 of 108 were found not to be atopic. The strength of the associations between wheeze and bronchial responsiveness to methacholine and between wheeze and atopy appeared to be greater in the presence of shortness of breath but these were not significant observations. A significant association was found between bronchial responsiveness to methacholine and the symptom group 'cough alone' $(p<0.02)$ but this did not correlate with the presence of atopy. The small number of children in the shortness of breath alone group prevented adequate assessment of the significance of the symptom on this analysis.

The results of the questionnaire survey showed that wheeze, cough, and shortness of breath were all associated with each other $(p<0.001$ for each association controlling for the remaining symptom group). The data were therefore further analysed by respiratory symptom (wheeze, cough, or shortness of breath) controlling for the presence of the other two symptoms. This also allowed us to examine all children in groups 4 and 5 (table 1) with respect to shortness of breath by controlling for wheeze and cough. In this analysis wheeze remained strongly related to both bronchial responsiveness to methacholine $(p<0.0001)$ and atopy $(p<0.0001)$ when controlling for the symptoms of cough and shortness of breath. By contrast, when controlling for wheeze, the symptoms of cough, shortness of breath, and 'bronchial irritability' all failed to show significant associations with either bronchial responsiveness to methacholine or atopy (tables 2 and 3 ).

We had previously found that bronchial responsiveness and atopy were closely related even when controlling for symptoms. ${ }^{12}$ We therefore tested the independence of the associations between wheeze and atopy and between wheeze and bronchial responsiveness to methacholine. Overall wheeze remained strongly related to atopy when controlling

Table 2 Effect of wheeze on the proportion of children with bronchial responsiveness to methacholine controlling for the presence of other symptoms

\begin{tabular}{lll}
\hline & $\begin{array}{l}\text { Wheeze absent } \\
\%(\mathrm{No})^{*}\end{array}$ & $\begin{array}{l}\text { Wheeze present } \\
\%(\mathrm{No})^{*}\end{array}$ \\
\hline $\begin{array}{l}\text { Shortness of breath: } \\
\text { Absent }\end{array}$ & $\begin{array}{l}20 \cdot 7(198) \\
\text { Present }\end{array}$ & $54 \cdot 9(51)$ \\
$\begin{array}{l}\text { Cough: } \\
\text { Absent }\end{array}$ & $64.9(57)$ \\
Present & $17 \cdot 3(150)$ & $65 \cdot 4(26)$ \\
Bronchial irritability: & $27 \cdot 8(72)$ & $58 \cdot 5(82)$ \\
$\quad$ Absent & & \\
Present & $16 \cdot 0(106)$ & $87.5(8)$ \\
\hline
\end{tabular}

*Percentage of number of children tested (No) with each symptom combination who displayed bronchial responsiveness to methacholine.

Mantel-Haenszel tests: wheeze $v$ bronchial responsiveness to methacholine controlling for shortness of breath, cough, and bronchial irritability: $p<0 \cdot 0001$; shortness of breath, cough, and bronchial irritability $v$ bronchial responsiveness to methacholine controlling for wheeze: all not significant.

Table 3 Effect of wheeze on the proportion of children with atopy controlling for the presence of other symptoms

\begin{tabular}{lll}
\hline & $\begin{array}{l}\text { Wheeze absent } \\
\%(N o)^{*}\end{array}$ & $\begin{array}{l}\text { Wheeze present } \\
\%(N o)^{*}\end{array}$ \\
\hline $\begin{array}{l}\text { Shortness of breath: } \\
\text { Absent }\end{array}$ & $\begin{array}{l}23.0(200) \\
\text { Present }\end{array}$ & $\begin{array}{l}60.4(48) \\
\text { Cough: }\end{array}$ \\
$\begin{array}{l}\text { Absent } \\
\text { Present }\end{array}$ & $22.7(24)$ & $70.2(57)$ \\
$\begin{array}{l}\text { Bronchial irritability: } \\
\text { Absent } \\
\text { Present }\end{array}$ & $29.6(71)$ & $76.0(25)$ \\
\hline
\end{tabular}

*Percentages of number of children tested (No) with each symptom combination who displayed atopy.

Mantel-Haenszel tests: wheeze $v$ atopy controlling for shortness of breath, cough, and bronchial irritability: $p<0 \cdot 0001$; shortness of breath, cough, and bronchial irritability $v$ atopy controlling for wheeze: all not significant. 
for the presence of bronchial responsiveness to methacholine $(p<0.0001)$ and to bronchial responsiveness to methacholine when controlling for atopy $(\mathrm{p}<0.0001)$. It was clear during this analysis, however, that wheeze was not related to atopy in the absence of bronchial responsiveness to methacholine or to bronchial responsiveness to methacholine in the absence of atopy (tables 4 and 5). Thus while 57 of $69(82.6 \%)$ atopic children with wheeze displayed the characteristic of bronchial responsiveness to methacholine, this was only true of five of 35 $(14.3 \%)$ children with wheeze but who were not atopic (table 4$)$. Similarly 57 of $62(91.9 \%$ ) wheezers with bronchial responsiveness to methacholine were atopic compared with 12 of $42(28.6 \%)$ of those who did not respond to methacholine. In the absence of atopy (table 5), more children with any reported respiratory symptom displayed bronchial responsiveness to methacholine compared with asymptomatic children but this difference just failed to reach significance (Fisher's exact test: $p=0.074$ ).

A comparison was made between the two age groups of children with the current symptom of wheeze with respect to the presence or absence of the combination of bronchial responsiveness to methacholine and atopy. It was found that $61.5 \%$ $(24 / 39)$ of the 7 year old children with wheeze did not have both of these characteristics while this figure decreased to $35 \cdot 4 \%(23 / 65)$ in the 11 year olds

Table 4 Effect of wheeze on the proportion of children with atopy controlling for the presence of bronchial responsiveness to methacholine

\begin{tabular}{llll}
\hline & $\begin{array}{l}\text { Wheeze } \\
\text { absent } \\
\%(\mathrm{No})^{*}\end{array}$ & $\begin{array}{l}\text { Wheeze } \\
\text { present } \\
\%(\mathrm{No})^{*}\end{array}$ & $\begin{array}{l}p \text { Value } \\
\left(\chi^{2}\right)\end{array}$ \\
\hline $\begin{array}{l}\text { Atopy absent } \\
\text { Atopy present }\end{array}$ & $\begin{array}{l}15 \cdot 4(162) \\
35.7(56)\end{array}$ & $\begin{array}{l}14 \cdot 3(35) \\
82.6(69)\end{array}$ & $\begin{array}{l}\text { NS } \\
<0.001\end{array}$ \\
\hline
\end{tabular}

*Percentages of number of children tested (No) with each combination who displayed bronchial responsiveness to methacholine.

Table 5 Effect of wheeze on the proportion of children with bronchial responsiveness to methacholine controlling for the presence of atopy

\begin{tabular}{|c|c|c|c|}
\hline & $\begin{array}{l}\text { Wheeze } \\
\text { absent } \\
\%(N o)^{*}\end{array}$ & $\begin{array}{l}\text { Wheeze } \\
\text { present } \\
\%(N o)^{*}\end{array}$ & $\begin{array}{l}p \text { Value } \\
\left(\chi^{2}\right)\end{array}$ \\
\hline \multicolumn{4}{|l|}{$\begin{array}{l}\text { Bronchial responsive- } \\
\text { ness to methacholine: }\end{array}$} \\
\hline Absent & $20 \cdot 8(173)$ & $28 \cdot 6(42)$ & NS \\
\hline Present & $44.4(45)$ & $91.9(62)$ & $<0.001$ \\
\hline
\end{tabular}

*Percentages of number of children tested (No) with each combination who displayed atopy. $(p=0 \cdot 017)$. Although failing to reach significance, these figures suggest that a fall in the prevalence of wheeze which is unassociated with bronchial responsiveness to methacholine and atopy may occur between 7 and 11 years mirroring the fall in the prevalence of cough. ${ }^{1}$

\section{Discussion}

We have performed a questionnaire survey of respiratory symptoms including wheeze among over 2500 schoolchildren of 7 and 11 years and in nearly 330 have performed tests of bronchial response to methacholine and skin sensitivity to three common allergens with the aim of discovering the associations between these variables and suggesting their role in the epidemiological definition and study of asthma.

Two factors examined in the first paper were found to be strongly related to the prevalences of respiratory symptoms ${ }^{11}$ : the presence of parental asthma and the sex of the responder to the questionnaire. We have not controlled for either of these factors which did not, in any case, enter into our randomised selection of children for testing. Either parental asthma or sex of responder might result in over or under reporting of symptom prevalences. In simple terms, this means that either could affect the precision with which the parent has answered the questionnaire. Clearly, this is not measurable and could be altered by any number of other factors. Imprecision may have blurred some weak associations but is not likely to have strengthened those described in this report or created associations which are not there-this would be a matter of chance which, therefore, has been measured by the statistical tests described. Although parents were told that testing would take place on some of the children, the nature of the tests was not outlined in the literature accompanying the initial questionnaire. Clearly, parents could not, in any case, have known the results of the tests to be performed on their children the following term. It is possible that the relationship between the sex of the responder to the questionnaire and the symptoms reported represents under or over reporting by fathers and mothers respectively. However, informal discussion with parents who attended with their children revealed a tendency for the mother or both parents together to complete the questionnaire if the child suffered significant symptoms.

The data presented in this and the preceding papers include a number of interesting negative findings. Mortagy et al were successful in finding a group of respiratory symptoms within the adult 
population which appeared to be universally associated with a defined degree of bronchial responsiveness (nocturnal dyspnoea, morning tightness lasting longer than one hour, and shortness of breath or wheeze in response to environmental irritants and cold). One of the aims of the present study was to find a similar group of symptoms which could be reported by parents in their children. In view of the close associations found by Mortagy et al, ${ }^{18}$ it was surprising to find that none of the symptoms described by the latter group, or any symptom other than wheeze, could be shown to have any separate association with either bronchial responsiveness or atopy. Our inability to corroborate the findings of Mortagy et al may indicate a difference between the paediatric and adult populations. Alternatively, it may simply indicate the fundamental difference between the subjective reporting of symptoms by adults and the objective nature of parent's observations. The children within our study population, however, were within an age range who would be able to report their symptoms to their parents. It is likely that further studies in adults, which may or may not corroborate the findings of Mortagy et al, will be required before these questions can be answered.

The absence of an association between symptoms other than wheeze and either methacholine bronchial responsiveness or atopy mirrored our previous finding that neither cough nor shortness of breath were related to parental asthma when we controlled for the symptom of wheeze. ${ }^{11}$ This finding was not altered by confining our analyses to symptoms occurring at night or in the morning or in response to environmental irritants. In view of the commonplace occurrence of both shortness of breath and cough in known asthmatics, this is an unexpected finding. In contrast, the associations between wheeze and parental asthma, bronchial responsive to methacholine and atopy were highly significant. Although children with asthma may present with the symptoms of cough or shortness of breath, most if not all of these will be found to have the additional symptom of wheeze on direct questioning. In the absence of wheeze, these findings indicate that the significance of cough or shortness of breath in relation to the diagnosis of asthma should be regarded with caution in future epidemiological work in children, although their usefulness as markers of morbidity is not in doubt. These data would also suggest that the treatment of children, who complain of recurrent cough, for asthma when there are no other indicators of the disease should be regarded with circumspection particularly in view of the commonness of this symptom. ${ }^{11}$

This study has shown an intriguing inter-relation- ship between the symptom of wheeze and the characteristics of bronchial responsiveness to methacholine and atopy. We have previously shown that bronchial responsiveness to methacholine and atopy remained strongly associated when controlling for wheeze, suggesting either a causal interaction or a common defect. The associations between wheeze and both bronchial responsiveness and atopy are well known. However, in this report we have shown that wheeze was quite unrelated to bronchial responsiveness to methacholine in the absence of atopy, despite a highly significant association among atopic children. Similarly wheeze was only related to atopy in the presence of bronchial responsiveness to methacholine but not otherwise. It would thus appear that the joint presence of these two phenomena is necessary for the manifestation of the symptom of wheeze and may represent a distinct pathological entity which is likely to be closely related to the clinical diagnosis of asthma. It is, of course, unlikely that $\mathrm{PD}_{20}$ of $6.4 \mu \mathrm{mol}$ represents a precise point below which wheeze and atopy are related; however, most responsive children had a $\mathrm{PD}_{20}$ between 1.6 and $6.4 \mu \mathrm{mol}$ suggesting that a cut off point broadly exists within this range. Children below this range might be described as 'hyper-responsive' because of the close association with atopy and recurrent wheeze indicating a pathological state. A fixed cut off only represents a statistical risk factor, however, and the occurrence and severity of wheeze, even in the presence of high degrees of bronchial responsiveness and atopy, is likely to depend upon a number of additional factors.

Overall, just over half of the children with wheeze whom we tested did not display both bronchial responsiveness to methacholine and atopy. Furthermore, many children suffered with respiratory symptoms other than wheeze particularly cough. It is likely that these children occupy more than one pathological entity. It was noted in the first study that, whereas there was a sharp decline in the prevalence of cough between 7 and 11 years, the prevalence of wheeze remained unchanged. Data presented in this paper suggest that there is likely to be a parallel decline in the prevalence of wheeze when it is not associated with the combination of atopy and bronchial responsiveness to methacholine. It is now well known that children suffering a variety of respiratory insults in early life, particularly respiratory syncytial virus bronchiolitis, may have persisting respiratory problems into early school age which have usually almost resolved by the age of 10 years. ${ }^{4}$ More recent studies have shown that these children are not more atopic than the normal population and do not have a stronger family history 
of asthma. ${ }^{6}$ It is likely that the group of children in this study who suffered cough and wheeze unassociated with bronchial responsiveness to methacholine or atopy includes such children with symptoms subsequent to viral or other infections in infancy, and the decline in prevalence of these symptoms represents the gradual resolution reported in other studies.

We also showed a likely but again just not significant association between respiratory symptoms generally and bronchial responsiveness to methacholine in the absence of atopy. It is possible that the latter children are suffering intermittent bronchial responsiveness to methacholine-for instance, in association with viral upper respiratory tract infections. This would be more difficult to show on a single measurement and the symptoms less easy to distinguish. Certainly this study showed a high background level of bronchial responsiveness to methacholine with no associated atopy or wheeze which is otherwise difficult to explain. Many young children who later develop classical asthma symptoms wheeze only after upper respiratory tract infections with apparent complete normality between attacks. In the past this condition has been labelled 'wheezy bronchitis' but more recently has been shown to be indistinguishable from asthma in terms of allergy, family history, and prognosis. ${ }^{19}$ It is possible that tests for atopy and perhaps serial measurements of bronchial responsiveness could be used to distinguish these children from those with symptoms subsequent to bronchiolitis and thus provide information on prognosis and perhaps treatment of the various forms of intermittent inflammatory airway disease. By performing a cross sectional survey, we have examined all our subjects over a short period of time. We have thus avoided possible differences between the two age groups which could occur as a result of year to year environmental alterations such as weather changes and fluctuations in the prevalences of viral and other respiratory infections. However, this study cannot provide information on changes occurring within individual children. A longitudinal study would be necessary to further test these hypotheses and firmly establish the natural history of the symptom subgroups in relation to atopy and bronchial hyperresponsiveness.

In the two previous papers we have shown a strong association between wheeze and the symptoms of cough and shortness of breath confirming their importance in the symptomatology of asthma. The lack of a separate association between cough, shortness of breath, or bronchial irritability as defined by Mortagy et $a l,{ }^{18}$ and any of bronchial responsiveness, atopy, or parental asthma when controlling for wheeze, indicates that these symptoms are not useful as epidemiological markers of the diséase in childhood. We have shown a number of significant changes between the ages of 7 and 11 years, including a fall in the prevalence of cough, an increase in the prevalence of atopy, and a fall in bronchial responsiveness to methacholine, with no associated changes in the prevalence of wheeze. We have been able to separate out from this confusing picture a distinct entity characterised by wheeze in association with both atopy and a bronchial response to low doses of methacholine. Whether this syndrome represents a distinct entity or deserves the label 'asthma' is a matter of conjecture at present and clearly warrants further study.

The authors would like to thank Mrs L Jackson for performing the allergen skin tests, Mr M Mullee for his valuable help with the computing, and Dr M Campbell for helpful statistical advice.

The work was supported by a project grant from the Asthma Research Council.

\section{References}

1 Gregg I. Epidemiological aspects. In: Clark T, Godfrey S, eds. Asthma. 2nd ed. London: Chapman and Hall, 1983:242-78.

2 Speight ANP, Lee DA, Hey EN. Underdiagnosis and undertreatment of asthma in childhood. Br Med J 1983;286:1253-6.

${ }^{3}$ Simms DG, Downham MAPS, Gardner PS, Webb JKG, Weightman D. Study of 8 year old children with a history of respiratory syncitial virus bronchiolitis in infancy. $\mathrm{Br} \mathrm{Med} \mathrm{J}$ 1978;i:11-4.

${ }^{4}$ Pullen CR, Hey EN. Wheezing, asthma and pulmonary dysfunction 10 years after infection with respiratory syncitial virus in infancy. $\mathrm{Br}$ Med $J$ 1982;284:1665-9.

5 Johnston IDA, Bland JM, Ingram D, Anderson HR, Warner JO, Lambert HP. Effect of whooping cough in infancy on subsequent lung function and bronchial reactivity. $A m \mathrm{Rev}$ Respir Dis 1986;134:270-5.

6 Sims DG, Gardner PS, Weightman D, Turner MW, Soothill JF. Atopy does not predispose to RSV bronchiolitis or post bronchiolitic wheezing. Br Med J 1981;282:2086-8.

7 Webb MSC, Henry RL, Milner AD, Stokes GM, Swarbrick AS. Continuing respiratory problems three and a half years after acute viral bronchiolitis. Arch Dis Child 1985;60:1064-7.

${ }^{8}$ Woolcock AJ, Dowse GK, Temple K, Stanley H, Alpers MP, Turner KJ. The prevalence of asthma in the South-Fore people of Papua New Guinea. A method for field studies of bronchial reactivity. Eur J Respir Dis 1983;64:571-81.

9 Salome CM. Peat JK. Britton WJ, Woolcock AJ. Bronchial hyperresponsiveness in two populations of Australian schoolchildren-1. Relation to respiratory symptoms and diagnosed asthma. Clin Allergy 1987;17:271-81.

11 Lee DA. Winslow NR, Speight ANP. Hey EN. Prevalence and spectrum of asthma in childhood. Br Med J 1983;286:1256-8.

"Clifford RD, Radford M, Howell JB, Holgate ST. Prevalence of respiratory symptoms among 7 and 11 year old schoolchildren and association with asthma. Arch Dis Child 1989;64:1118-25.

12 Clifford RD, Radford M, Howell JB, Holgate ST. Prevalence of atopy and range of bronchial response to methacholine in 7 and 11 year old schoolchildren. Arch Dis Child 1989;64:1126-32.

1.3 Yan K. Salome C, Woolcock AJ. Symptoms, atopy, and bronchial response to methacholine in parents with asthma and their children. Arch Dis Child 1987:62:66-73.

${ }^{14}$ McCarthy OR. Selection of skin tests in asthma. Br J Dis Chest 1973:67:238-40. 
Respiratory symptoms, bronchial response to methacholine, and atopy in schoolchildren 1139

15 Russel G, Jones SP. Selection of skin tests in childhood asthma. Br J Dis Chest 1976;70:104-6.

16 SPSSx users guide. 2nd ed. New York: McGraw-Hill, 1986.

17 Snecdor GW, Cochran WG. Statistical methods. 6th ed. Iowa: Iowa State University Press, 1967:255-6.

${ }^{18}$ Mortagy AK, Howell JB, Waters WE. Respiratory symptoms and bronchial reactivity: identification of a syndrome and its relation to asthma. Br Med J 1986;293:525-9.

19 Williams H, McNicol KN. Prevalence, natural history and relationship of wheezy bronchitis and asthma in children. An epidemiological study. Br Med J 1969;iv:321-5.

Correspondence and requests for reprints to Dr RD Clifford, Institute of Child Health, Royal Hospital for Sick Children, St Michael's Hill, Bristol BS2 8BJ.

Accepted 17 January 1989

See p 1194. 